\title{
Spontaneous Resolution of Brain Edema in Fulminant Hepatic Failure due to Hepatitis E
}

\author{
Laurent Spahr ${ }^{a} \quad$ Isabelle Morard ${ }^{a} \quad$ Gilles Mentha ${ }^{b}$ \\ Antoine Hadengue $^{a}$ Emiliano Giostra ${ }^{a}$ \\ ${ }^{\mathrm{a}}$ Gastroenterology and Hepatology and ${ }^{\mathrm{b}}$ Transplantation Unit, University Hospital, \\ Geneva, Switzerland
}

\section{Key Words}

Fulminant hepatic failure $\cdot$ Hepatic encephalopathy $\cdot$ Hepatitis E · Brain edema $\cdot$ Liver transplantation

\begin{abstract}
Fulminant hepatic failure is characterized by the presence of hepatic encephalopathy in the setting of acute liver injury that occurs in a noncirrhotic organ. Brain edema is the ultimate complication of advanced hepatic encephalopathy as it often leads to cerebral herniation and death. Thus, the presence of fulminant hepatic failure indicates the need for urgent liver transplantation to prevent death or irreversible brain damage. We report a very unusual evolution of fulminant hepatic failure complicated by brain edema and hepatic coma in a 45-year-old woman admitted with acute viral hepatitis E infection.
\end{abstract}

\section{Case Report}

A 45-year-old woman was admitted to our hospital 9 days after the apparition of asthenia and progressive jaundice. She was working as a nutritionist in the Darfur region of western Sudan, had no personal or family history of liver disease and was not consuming illicit drugs or alcohol. She had received hepatitis A and B vaccines. The day prior to transfer in Geneva, she developed grade IV hepatitis E, was electively intubated and given intravenous mannitol. Computed tomography showed a grossly normal liver with patent hepatic veins and ascites. Diffuse cerebral edema was evident both at cranial computed tomography and MRI scans (fig. 1). Laboratory values were as follows: aspartate aminotransferase $436 \mathrm{IU} / \mathrm{l}(\mathrm{N}: 1-42)$, alanine aminotransferase 1,813 IU/l (N: 9-42), total bilirubin $436 \mu \mathrm{mol} / \mathrm{l}(\mathrm{N}:$ 7-25), alkaline phosphatase $107 \mathrm{IU} / \mathrm{l}$ (N: 30-125), ammonium $118 \mu \mathrm{mol} / \mathrm{l}$ (N: 11-35), creatinine $72 \mu \mathrm{mol} / \mathrm{l}(\mathrm{N}: 35-88)$, phosphate $0.63 \mathrm{mmol} / \mathrm{l}(\mathrm{N}: 0.8-1.5)$, prothrombin time $59 \mathrm{~s}$, INR 6 , and factor V 20\%. Alpha fetoprotein level was $219 \mathrm{ng} / \mathrm{ml}(\mathrm{N}:<15)$. She tested negative for autoimmune, toxic and metabolic diseases as well as for hepatitis A, B, C, and HIV. However, high titers of anti-HEV antibodies (enzyme immunoassay Abbott HEV EIA) were detected in the serum. The levels of anti-HEV IgG and IgM were 3,000 (threshold level at 520) and 1,848 (threshold level at 420) optical densities, 
respectively. There was no evidence of infection. Thus, in the presence of acute liver failure (factor $\mathrm{V}$ $<30 \%$ ) complicated by rapid neurological deterioration and brain edema on imaging studies, spontaneous survival was estimated below $10 \%$ according to Clichy's criteria [1], and the patient was listed for urgent liver transplantation while receiving standard supportive care but no hypothermia or liver support device. She remained stable during the two following days and progressively started to breathe spontaneously and to respond to painful stimuli. Figure 1 illustrates the spontaneous progressive improvement in biological tests starting from day 2 of hospital admission. She was then delisted. On day 4, she was fully conscious and oriented. Brain edema had completely resolved on repeat cranial MRI. The neurological status was normal at hospital discharge on day 22.

\section{Discussion}

Hepatitis E virus is a frequent cause of acute hepatitis in developing countries [2]. High mortality was initially described in pregnant women from endemic countries, but sporadic cases [3], sometimes fatal [4], have been described both in males and nonpregnant females from Western Europe. In acute liver failure, prognostic markers that dictate the need for urgent liver transplantation include the King's College and Clichy's criteria [1], and more recently the MELD [5]. Our patient fulfilled all these criteria. Although useful, these tools are not $100 \%$ accurate in predicting spontaneous outcome. Factors that may positively influence the course of the hepatitis include viral cause, hyperacute presentation, elevated AFP and no infection, while the presence of profound hepatitis E complicated by cerebral edema is clearly associated with a poor prognosis without urgent liver transplantation.

Whether the particular evolution of our case with fulminant hepatic failure relates to host factors or to the causative agent remains unclear. Neurological symptoms associated with hepatitis E include meningoencephalitis with seizures [6] and spontaneously reversible grade III hepatitis $\mathrm{E}$ in the setting of both acute liver and renal failure [7]. The combined action of acute hepatitis and associated hyperammonemia-induced increased permeability of the blood brain barrier may increase the risk of hepatitis $\mathrm{E}$ and brain edema [8].

Although the present case underlines the limitations of prognostic scoring in this life-threatening condition, the treatment of patients with fulminant hepatic failure remains urgent liver transplantation [9]. 
Fig. 1. Evolution of laboratory values over time since hospital admission in Geneva.

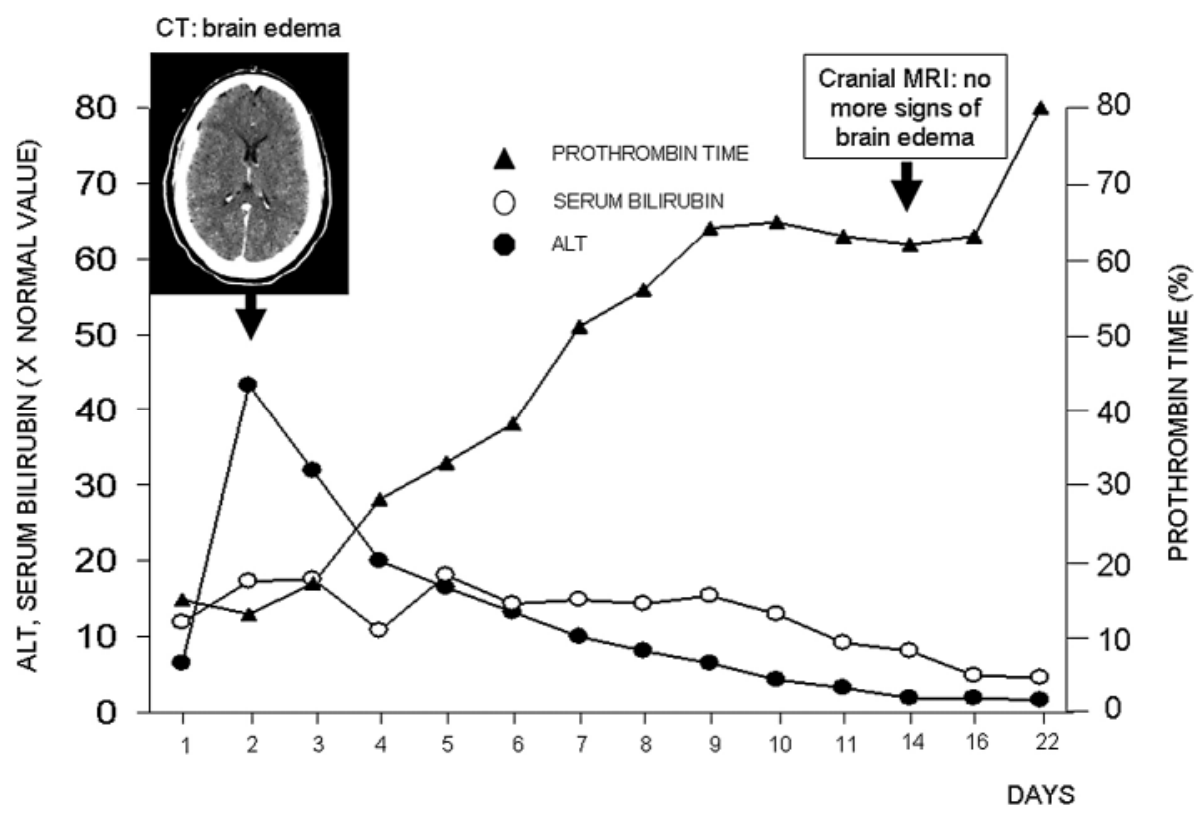




\section{References}

1 Pauwels A, Mostefa-Kara N, Florent C, Levy VG: Emergency liver transplantation for acute liver failure. Evaluation of London and Clichy criteria. J Hepatol $1993 ; 17: 124-127$

-2 Acharya SK, Dasarathy S, Kumer TL, Sushma S, Prasanna KS, Tandon A, Sreenivas V, Nijhawan S, Panda SK, Nanda SK, Irshad M, Joshi YK, Duttagupta S, Tandon RK, Tandon BN: Fulminant hepatitis in a tropical population: clinical course, cause, and early predictors of outcome. Hepatology 1996;23:1448-1455.

- 3 Moucari R, Bernuau J, Nicand E, Cazals-Hatem D, Valla D, Marcellin P, Asselah T: Acute hepatitis $E$ with severe jaundice: report of three cases. Eur J Gastroenterol Hepatol 2007;19:1012-1015.

4 Peron JM, Bureau C, Poirson H, Mansuy JM, Alric L, Selves J, Dupuis E, Izopet J, Vinel JP: Fulminant liver failure from acute autochthonous hepatitis $\mathrm{E}$ in France: description of seven patients with acute hepatitis $\mathrm{E}$ and encephalopathy. J Viral Hepat 2007;14:298-303.

-5 Yantorno SE, Kremers WK, Ruf AE, Trentadue JJ, Podesta LG, Villamil FG: MELD is superior to King's college and Clichy's criteria to assess prognosis in fulminant hepatic failure. Liver Transpl 2007;13:822-828.

6 Kejariwal D, Roy S, Sarkar N: Seizure associated with acute hepatitis E. Neurology 2001;57:1935.

-7 Verschuuren EA, Haagsma EB, Zijlstra JG, Stegeman CA: Non-oliguric acute renal failure associated with hepatitis E. Nephrol Dial Transplant 1997;12:799801.

8 Jalan R, Bernuau J: Induction of cerebral hyperemia by ammonia plus endotoxin: does hyperammonemia unlock the blood-brain barrier? J Hepatol 2007;47:168171.

9 Polson J, Lee WM: AASLD position paper: the management of acute liver failure. Hepatology 2005;41:1179-1197. 